\title{
Sistema de Informação e Cidadania - A falta de usabilidade pode tolher o exercício da democracia?
}

\author{
Marcelle Christina Lopes Gomes de Santana ${ }^{1}$, Cayley Guimarães ${ }^{1}$ \\ ${ }^{1}$ Departamento de Ciências Exatas e Tecnológicas - Centro Universitário de Belo \\ Horizonte (UNI-BH), Belo Horizonte -MG - Brasil \\ cellesantana@yahoo.com, profcayley@yahoo.com.br
}

\begin{abstract}
Resumo. Hoje a Internet se apresenta como fator que altera comportamentos sociais, inclusive relativos à democracia. Analisando a escolha de candidatos políticos, vê-se que o sistema de informação do candidato e sua campanha têm na Internet um vetor de universalização e inclusão. Nesta pesquisa avaliaram-se os sites dos candidatos a governador do Estado de Minas Gerais e constatou-se a falta de usabilidade dos sites, dificultando a obtenção das informações necessárias. Neste aspecto, observa-se um prejuízo à democracia pelo alijamento dos eleitores.
\end{abstract}

\section{Introdução}

Na Sociedade atual, altamente informatizada, a Internet pode se fazer útil em diferentes áreas de atuação. No âmbito político, ela pode servir como meio de divulgação das idéias dos candidatos através de seus sites.

Este trabalho busca analisar os sites dos candidatos políticos quanto à usabilidade, avaliando se eles estão sabendo utilizar os novos meios de comunicação como forma de fortalecer a democracia.

Desenvolvendo uma pesquisa com estudantes voluntários, foram avaliados os sites dos candidatos a governador do Estado de Minas Gerais e analisada se a existência ou não da usabilidade implica na debilitação da cidadania.

\section{Cidadania na era da Informação}

O conceito de cidadania é antigo e pode ser entendido a partir de análises das inspirações do mundo greco-romano, onde se definia cidadania a partir de idéias de: "democracia, participação popular nos destinos da coletividade, soberania do povo, liberdade do individuo” (GUARINELLO, 2003). Estas idéias modelaram os conceitos atuais de cidadania, definindo e delineando-os.

Hoje a cidadania plena está contida nos conceitos de direitos civis, políticos e sociais de uma pessoa. Analisando apenas os direitos políticos, pode-se dizer que eles implicam na participação de uma pessoa no destino da sociedade. Mais especificamente, o cidadão pode exercer o seu direito ao voto e a ser votado (PINSKY e PINSKY, 2003). Para exercer integralmente estes direitos, as pessoas devem estar munidas com as informações relevantes ao seu julgamento. Uma pessoa que pratica a democracia não pode prescindir de conhecimento e informação, sob pena do exercício da cidadania resultar incompleto, pois o cidadão não expressaria integralmente sua liberdade e sua vontade. 
O voto é um ato de cidadania, um símbolo da democracia, em que se permite ao cidadão o poder de expressar idéias e opiniões políticas de forma livre, escolhendo um candidato que apresenta afinidades com seus ideais para representá-lo (CANÊDO, 2003). E o eleitor, para achar o candidato que compartilha desses ideais, precisa obter informações sobre aqueles que estão concorrendo a um determinado cargo político.

Ao longo do tempo, os meios utilizados para os candidatos difundirem suas idéias veio evoluindo à medida que incorporavam novas formas de comunicação. Nos primórdios da democracia, as escolhas políticas se faziam através de discursos e debates em praça pública, à semelhança dos comícios atuais. Com a difusão da escrita, este recurso também passou a ser utilizado com objetivos políticos. Depois vieram ainda as novas tecnologias como o rádio e a televisão acrescentando novos espaços de comunicação e divulgação de idéias.

Atualmente, a Internet surge e se expande como o último e revolucionário estágio de evolução dos meios de comunicação. Com o rádio, houve uma massificação das campanhas. A televisão, além dessa massificação, acrescentou recursos visuais e de marketing que transformaram as campanhas em um espetáculo. Já a Internet é considerada como um meio de comunicação livre e engloba, além dessas possibilidades, novas perspectivas de expressão que, por exemplo, não se submetem as linhas editorias comuns aos órgãos de imprensa. Como diz Vint Cerf, um dos criadores da Internet: “A Internet é um dos mais poderosos agentes de liberdade. Ela mostra a verdade àqueles que querem vê-la... Cabe a cada um de nós saber distinguir o verdadeiro do falso" (ELIE, 2003).

Bernardo Sorj analisa a revolução tecnológica trazida pela Internet dizendo que ela permite uma comunicação instantânea, eliminando barreiras do espaço físico e propiciando a todos o acesso a uma nova realidade política e social. Ela permitiu que o manuseio da informação e da comunicação, duas das atividades centrais da vida, se convergissem apresentando possibilidades de participação descentralizada (SORJ, 2003). Pode-se dizer que ela oferece certa vantagem sobre os meios tradicionais e até mesmo se tornado ideal no que se refere a uma comunicação democrática.

Três fenômenos aproximam a Internet de uma esfera pública virtual: "ambiente de conexão", “complexo de conteúdos” e "sistema de interações” (GOMES, 2001; MAIA, 2002). Eles aproximam o cidadão cada vez mais de exercer através dela o seu direito político e, consequentemente, a democracia/cidadania.

No que se refere ao ambiente de conexão, o primeiro fenômeno, o cidadão tem na Internet um espaço para expor publicamente sua opinião, discorrer sobre o que concorda ou não e o que pode mudar e também receber e oferecer informações relevantes. No segundo, relativo à complexidade de conteúdos, a Internet oferece ao cidadão uma densa rede de dados e conteúdos de todas as naturezas sobre qualquer tema. Esta complexidade não vem sem custo: o uso e entendimento destes conteúdos, para que sejam produtivos, devem se fazer preceder por uma série de aspectos - acesso, domínio, compreensão, etc. Usabilidade, enfim. E finalmente no último fenômeno, o de sistema de interações, o cidadão pode interagir através de uma base direta, via correio eletrônico (e-mail), ou através de salas de conversa, listas de discussão e grupos de notícias com outros cidadãos e até mesmo com as entidades governamentais e os políticos. 
De tudo que foi dito se conclui que as novas tecnologias estão mudando a forma com que os eleitores se comunicam, interagem e obtém conhecimento quanto aos seus candidatos, facilitando o acesso às informações e, conseqüentemente, o melhor exercício da cidadania (FISHKIN, 2002).

\section{Sistema de Informação e Usabilidade}

De forma geral, um Sistema de Informação pode ser definido como um conjunto de componentes inter-relacionados ou um sistema automatizado capaz de coletar, recuperar, processar, transmitir, armazenar e disseminar dados e informações (LAUDON e LAUDON, 2004). Segundo José P. M. de Oliveira, o Sistema de Informação, ou S.I., desenvolve funções técnicas ou administrativas que fazem parte do dia-a-dia das pessoas. E por interagir diretamente com as pessoas, o sucesso de uma SI está diretamente ligado à sua integração com o ambiente social em que ele está inserido (OLIVEIRA, 2003).

É necessário que as novas tecnologias sejam úteis e apresentem uma boa interatividade com os seres humanos para que elas possam integrar socialmente, potencializando a qualidade de vida e a interação social (SORJ, 2003). Este conceito de integração homem-máquina se mistura à idéia de usabilidade.

De acordo com Scapin (1993), usabilidade envolve a habilidade do sistema em permitir que seus usuários sejam capazes de atingir facilmente seus objetivos de interação com o sistema. Para ele, problemas de usabilidade estão diretamente relacionados com o diálogo homem-computador. Carroll e Moran (1996) acrescentam dizendo que as principais características necessárias a um sistema para apresentar uma boa usabilidade são: facilidade de uso; fácil entendimento de como operar o mesmo para a execução da tarefa desejada; ter sucesso na execução das tarefas; percepção dos erros e recuperação dos mesmos.

Dessas afirmações é possível concluir então que um S.I. que não apresenta usabilidade terá grandes problemas em obter sucesso, pois seus usuários terão várias dificuldades e problemas para realizarem as tarefas desejadas. Este é inclusive um dos problemas que vem sendo enfrentado na Internet: a falta de usabilidade nos sites.

Os sites podem ser considerados sistemas de informações, pois eles possibilitam, de forma geral, a transmissão e disseminação de dados e criando o elo de interação entre o usuário e a Internet. A Internet é um instrumento de informação capaz de disponibilizar milhares de informações aos seus usuários. Porém a forma que essas informações são apresentadas aos usuários nos sites nem sempre oferece usabilidade, gerando assim dificuldades de interação.

Em uma entrevista para a revista Fonte (CAMARGOS, 2006), Jakob Nielsen, considerado um guru da usabilidade na web, defende a simplicidade e a praticidade na arquitetura de informação e navegação de sites. Ele evidencia através de testes e números onde os usuários acertam ou erram quando utilizam os sites e vale-se destes dados para desenvolver melhorias nos mesmos. Nielsen, nesta reportagem, cita o exemplo de um site de comércio eletrônico que mudou o antigo site e teve uma considerável queda nas vendas devido à falta de usabilidade do novo site. Este exemplo retoma a idéia apresentada anteriormente de que um S.I. que não apresenta usabilidade pode ter grandes problemas em obter sucesso. 
Por fim, não se pode esquecer que o ser humano tem de ser, em última análise, o objetivo final de qualquer tecnologia. E que uma boa interação entre o Sistema de Informação e o usuário é de fundamental importância.

\section{Sistema de Informação e a Política}

Como apresentado anteriormente, a Internet é uma eficaz fonte de conhecimento para as pessoas, capaz até de, à primeira vista, ser mais benéfica que os meios de comunicação tradicionais (MAIA, 2002). E hoje, segundo Sorj (2003), ela participa da vida das pessoas incrementando meios para que elas exerçam sua cidadania/democracia: aumentando a qualidade, transparência e fiscalização das ações e serviços do governo e das instituições públicas; incrementando novas formas de participação e influência nas gestões e decisões governamentais; e modificando a própria estrutura das organizações políticas da sociedade.

A organização política da sociedade no regime democrático se dá através da participação política popular pelo voto. Essa organização política é, portanto, precedida pelas campanhas eleitorais, quando os eleitores têm a chance de conhecer candidatos para cargos políticos, escolhendo aquele que mais se afina com seus anseios políticos. Por isso o acesso às informações sobre os candidatos é vital e é parte integrante do exercício da democracia.

A Internet participa da vida eleitoral dos cidadãos, à medida que eles podem utilizá-la para obter informações quanto aos candidatos através de seus sites, possibilitando, além da esfera pública apresentada, o nascimento de um novo cenário para várias novas estratégias políticas (RUBIM, 2001). Rubim observa inclusive no seu trabalho que "a instalação e o desenvolvimento da democracia nos espaços eletrônicos passam a ser requisitos fundamentais da possibilidade de se falar em democracia na contemporaneidade" e que "sem essas democratizações não existe efetivamente democracia hoje”.

Evidentemente todas as considerações acima só são válidas a partir do momento em que os sites tiverem boa usabilidade. Sites de candidatos não podem desconsiderar a usabilidade, pois talvez ignorar este fato possa levar à perda de eleitores, assim como no exemplo anterior o site de comercio eletrônico perdeu clientes por não ter usabilidade.

É importante que os eleitores consigam obter as informações por eles consideradas relevantes neste sites, senão eles deixam de cumprir seu objetivo causando um prejuízo à democracia. Este cenário de desconsideração da interação entre o eleitor e o site dos candidatos existe hoje?

\section{Pesquisa de Usabilidade}

Como foi apresentado nos capítulos anteriores, a Internet oferece um denso ambiente de informações e é uma ótima ferramenta para que o cidadão possa exercer a cidadania de várias formas, entre elas avaliando os candidatos a cargos públicos. Entretanto ainda não se sabe se os sites destes candidatos estão sendo desenvolvidos com a eficácia necessária paro o exercício dos direitos políticos. 


\subsection{Proposta de Pesquisa}

Existem vários fatores que justificam a exploração da Internet para fins comerciais como, por exemplo, explorar mercados sem se preocupar com qualquer limitação geográfica. Contudo existe também potencial para difundir não só as vendas, mas informações construtivas para formação ética, política e de cidadania das pessoas.

Para as eleições deste ano, Amaral ofereceu sugestões aos eleitores quanto à forma de se escolher o candidato. Entre elas, menciona a importância do eleitor definir sua posição política e o que espera do governo, procurando candidatos que melhor representarão seus ideais. $\mathrm{O}$ articulista ressaltou também que a Internet é uma ótima ferramenta para buscar informações sobre os candidatos nesta eleição. E não só ele, mas também outros autores, como Nelson de Sá, destacaram a Internet como uma nova arma de campanha (AMARAL, 2006; SÁ, 2006).

O percentual de brasileiros que acessam a Internet passou de 2,9\% em 2000, para 12,2\% em 2004, e Valter Pomar, secretário do PT, destacou que os internautas já seriam aproximadamente $30 \%$ do total do eleitorado neste ano, demonstrando que o acesso à Internet pelos eleitores está crescendo no Brasil. (CELESTINO, 2005; SÁ,2006). Se o candidato disponibilizar informações suficientes em seu site ele estará utilizando de forma adequada essa nova ferramenta.

Com objetivo de averiguar se existe usabilidade nos sites dos candidatos, foi realizada esta pesquisa. Acredita-se que a falta da usabilidade nos sites pode comprometer seriamente o exercício da cidadania/democracia.

\subsection{Realização de testes}

Aproveitando-se do meio acadêmico no qual esta pesquisa se desenvolveu, foi formado um grupo com 15 alunos voluntários do curso de Ciência da Computação do Centro Universitário de Belo Horizonte. Este grupo pode induzir a um viés no resultado da pesquisa, mas a comprovação da falta de usabilidade para um grupo com habilidade computacional acima da média pode até mesmo reforçar a tese defendida, uma vez que, se os sites não apresentam usabilidade para eles, logicamente terão ainda menos para um usuário comum.

Solicitou-se a cada voluntário do grupo que respondesse a um primeiro formulário, desenvolvido para esta pesquisa, que avaliaria seu perfil de usuário e o seu grau de inserção nas atividades sócio-políticas. Em seguida eles realizaram três tarefas relacionadas aos sites dos candidatos ao governo do Estado de Minas Gerais para a eleição neste ano de 2006. Não foi fornecido a eles nem o nome dos candidatos e nem o endereço eletrônico dos sites. Saber quais eram os candidatos foi a primeira tarefa, assim como descobrir o endereço da página principal do site de cada candidato e marcar quanto tempo eles despenderam para ter acesso a estas informações. As outras tarefas foram buscar, para cada candidato, o seu currículo no site e tentar encontrar uma proposta dos mesmos para a área de informática.

E por último, eles avaliaram a usabilidade dos sites quanto às categorias de design, aparência, navegabilidade, qualidade de informação e consistência de funções. 


\subsection{Resultados}

Avaliando-se os resultados do primeiro formulário, alguns dados podem ser abstraídos:

- A média da idade dos voluntários é de 24 anos; todos tinham o ensino superior incompleto, mas trabalhavam em várias áreas dentro da informática;

- Mais de 90\% deles utilizavam a Internet diariamente para diferentes objetivos, mostrando ser este grupo um público com grande acesso à Internet. Entre estes objetivos a pesquisa, o acesso ao correio eletrônico e a baixa de arquivos foram os mais frequentemente mencionados;

- Quanto à freqüência com que assistem ao programa eleitoral: 40\% responderam que não assistem; $50 \%$ responderam que assistem raramente; $10 \%$ responderam que assistem esporadicamente;

- Quanto a sua participação na militância política, nenhum deles é afiliado a partido político e apenas 20\% têm um parente ou amigo candidatando nas eleições de 2006;

- Avaliando as informações relevantes para se escolher um candidato, este grupo considerou importante: o programa de governo, as contribuições prévias e os serviços prestados, o histórico/currículo, os antecedentes e os cargos já ocupados;

- Avaliando os meios de comunicação, o grupo considerou o rádio, a televisão, a opinião de amigos e parentes, as notícias de revistas e de jornais e a Internet como sendo todos relevantes, mas não essenciais;

- 50\% do grupo já havia visitado sites de candidatos duas ou mais vezes e os outros 50\% não o fez ou por desinteresse ou falta tempo.

Já quanto à realização das tarefas, foram obtidos os seguintes resultados:

- Os candidatos ao governo do Estado de Minas Gerais apresentados pelo grupo foram Aécio Neves e Nilmário. O tempo médio para descobrir o endereço eletrônico do site destes candidatos foi de um minuto e de um minuto e quarenta segundos respectivamente. Tempo longo para a Internet, pois obter rapidamente informações faz parte de uma boa usabilidade. Grande parte do grupo procurou pelos sites em páginas de pesquisa e tiveram que analisar os resultados para achar o site oficial, pois a maioria deles era de notícias sobre o candidato e ninguém mencionou que o site do candidato apareceu como primeira opção do resultado de busca. Mas algumas considerações importantes de alguns voluntários foram que não conseguiram através dos sites dos partidos dos candidatos informações ou acesso aos sites dos mesmos; e que no caso do candidato Aécio Neves a extensão '.can.br’ ao invés de ‘.com.br’ os deixou em dúvida se este poderia ser um site válido para o candidato ou se seria um site falso;

- A tarefa de buscar o currículo do candidato não foi concluída com sucesso por 15\% do grupo para os dois candidatos e o tempo médio de busca, tanto para quem achou como para quem não achou e desistiu, foi de um minuto para os dois candidatos. A tarefa de buscar uma proposta para a área de informática não foi concluída com sucesso por $35 \%$ do grupo quanto ao site do Aécio Neves e por $40 \%$ quanto ao do Nilmário. O tempo médio de busca foi de dois minutos para os dois candidatos, que é um tempo longo em se tratando de Internet. 
E finalmente, quanto à avaliação de usabilidade, nenhum dos dois sites, como se pode ver na Figura 1, obteve nota superior a 3. O site do candidato Aécio Neves obteve notas médias entre 1 e 2, e o do candidato Nilmário, notas médias entre 2 e 3 , para todas as categorias avaliadas, mostrando assim que nenhum dos dois sites apresenta usabilidade satisfatória (Considerou-se a escala Likert para qualificar a avaliação subjetiva: 0 muito ruim, 1 ruim, 2 regular, 3 boa - mas precisa melhorar, 4 boa e 5 ótima. E as categorias numeradas como: 1 - design, 2 - aparência, 3 - navegabilidade, 4 - qualidade de informação, 5 - consistência de função).

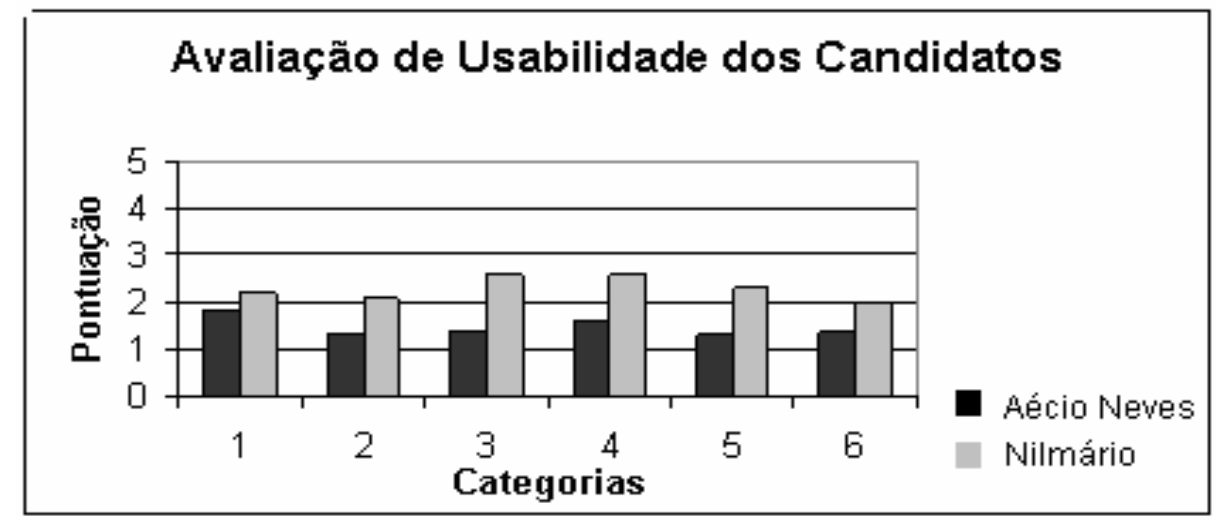

Figura 1. Gráfico representativo da avaliação do site dos candidatos

\section{Conclusão}

Avaliando os resultados foi possível reafirmar a idéia de alguns autores e concluir através deles que os sites dos candidatos políticos analisados não apresentam usabilidade. Devido à ausência de usabilidade nos mesmos, os candidatos não estão fornecendo, ou os eleitores não estão obtendo, informações necessárias a uma tomada de posição política. Como a informação é elemento chave na atual sociedade, a falta de usabilidade que impede o acesso da informação de um sistema de informação de um candidato em campanha política pode ser fator inibidor da democracia, na forma de alijamento do cidadão de uma participação efetiva no processo.

\section{Referências}

AMARAL, F. (2006), "Como escolher o melhor candidato”, In Revista Super Interessante, Edição 230, páginas 41-42. Editora Abril.

CAMARGOS, A.P. (2006), "Usabilidade: o lado humano da inovação tecnológica", Entrevista com Jakob Nielsen, In Revista Fonte, Volume 4.

CANÊDO, L. B. (2003) “Aprendendo a Votar”, In Historia da Cidadania, Organizado por Jaime Pinsky e Carla Bassanezi Pinsky, Editora Contexto.

CARROLL, J.M. e MORAN, T.P. (1996), Desing Rationale: concepts, techniques, and use. New Jersey: LEA.

CELESTINO, T. (2005) "Brasil entre os 10 colocados, mas ainda precisa crescer", In XMstudio, acessada em 6 de outubro de 2006, disponível em http://www.mxstudio.com.br/views.tutorial.php?act=view\&cid=4\&aid=727. 
ELIE, M. (2003), "Internet e desenvolvimento - um acesso à informação com mais eqüidade?”, In Internet e Política, Organizado por José Eisenberg e Marco Cepik, Editora UFMG, Belo Horizonte, MG, Brasil.

FISHKIN, J. S. (2002) "Possibilidades Democráticas Virtuais”, In Internet e Política, Organizado por José Eisenberg e Marco Cepik, Editora UFMG, Belo Horizonte, MG, Brasil.

GOMES, W. (2001), “Opinião Política na Internet”, Acessada em 6 de outubro de 2006, Disponível em http://www.unb.br/fac/comunicacaoepolitica/Wilson2001.pdf\#search =\%22GOMES\%20opini\%C3\%A3o\%20p\%C3\%BAblica\%20NA\%20INTERNET\%22

GUARINELLO, N. L. (2003) “Cidades-estado na Antigüidade Clássica”, In Historia da Cidadania, Organizado por Jaime Pinsky e Carla Bassanezi Pinsky, Editora Contexto.

LAUDON, K. C. e LAUDON, J. P. (2004) Sistemas de Informações Gerenciais: administrando a empresa digital, $5^{a}$ edição, São Paulo Perarson/Prentice Hall.

MAIA, R. C. M. (2002) "Redes Cívicas e Internet - do ambiente informativo denso à condições da deliberação pública”, In Internet e Política, Organizado por José Eisenberg e Marco Cepik, Editora UFMG, Belo Horizonte, MG, Brasil.

OLIVEIRA, J. P. M. (2003) "Sistemas de Informação e Sociedade”, In Ciência e Cultura, Acessada em 6 de setembro de 2006, Disponibilizada em http://cienciaecultura.bvs.br/scielo.php?pid=S0009-

67252003000200023\&script=sci_art text.

PINSKY, J. e PINSKY, C. B. (2003) Historia da Cidadania, Organizado por Jaime Pinsky e Carla Bassanezi Pinsky, Editora Contexto.

RUBIM, A. A. C. (2001), “O lugar da política na sociedade contemporânea”, In Lugar Global e Lugar Nenhum, Organizado por José Luiz Aidar Prado e Liv Sovik, Hackers Editores.

SÁ, N. (2006), Folha de São Paulo, Caderno Informática, páginas F1, F3-F5. Data 9 de agosto de 2006.

SCAPIN, D.L. (1993) The need for a psycho-engineering approache to HCI, In: Anais do Segundo congresso latino-americano e sexto seminário brasileiro de ergonomia. Florianópolis (Santa Catarinha), ABERGO/FUNDACENTRO, 03-22.

SORJ, B. (2003) Brasil@povo.com, Jorge Zahar Editor. 